\title{
TRADUÇÃO COMENTADA DO CONTO MA MÈRE ET LES LIVRES, DE COLETTE
}

\section{COMMENTED TRANSLATION OF THE SHORT STORY MA MÈRE ET LES LIVRES, BY COLETTE}

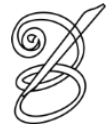 \\ Jaqueline Sinderski BIGATON* \\ Univesidade Federal de Santa Catarina \\ Sheila Cristina dos SANTOS** \\ Univesidade Federal de Santa Catarina
}

\begin{abstract}
Resumo: O presente artigo propõe a tradução inédita para o português brasileiro do conto "Ma mère et les livres", publicado no livro La maison de Claudine, de Sidonie-Gabrielle Colette, com o intuito de refletir a prática de tradução estrangeirizante, fundamentada nas reflexões de Antoine Berman (2013), acerca dos objetivos éticos da tradução, da letra e do lugar do estrangeiro na cultura e língua de chegada. A partir da tradução proposta, será apresentada uma análise das escolhas feitas durante a prática tradutória, cujo objetivo é, além de refletir sobre o processo de tradução, abrigar o Outro, o estrangeiro, no texto traduzido, aproximando o leitor de chegada ao universo cultural do texto de partida.
\end{abstract}

Palavras-chaves: Colette. Literatura francesa. Tradução estrangeirizante. Tradução literária comentada.

Abstract: The following article proposes the unpublished translation to Brazilian Portuguese of the short story "Ma mère et les livres", published in the book La maison de Claudine, from author Sidonie-Gabrielle Colette, with the intent of reflecting on the foreignizing translation practice, grounded in the reflections of Antoine Berman (2013) about the ethical objectives of translation, the letter and the place of the foreigner in the culture and in the target language. From the proposed translation, an analysis will be presented about the choices made during the translational practice, whose objective is to, beyond reflecting about the translation process, shelter the Other, the foreigner, in the translated text, bringing the target reader closer to the cultural universe of the source text.

Key-words: Colette. French literature. Foreignizing translation. Commented literary translation.

\section{A ingênua Colette}

idonie-Gabrielle Colette, nascida em 1873, foi criada no interior da França, em SaintSauveur-en-Puisaye, e as memórias de uma infância, cercada pela família - seus três irmãos mais velhos, seu pai e sobretudo sua mãe, a quem Colette idolatrava e chamava carinhosamente de Sido -, assim como pela natureza campestre, pelos animais domésticos e pelos livros (BOURIN e ROUSSELOT, 1966), permeiam a construção dos textos que figuram em La Maison de Claudine. É possível encontrar na própria obra de Colette o conceito da infância como uma "paisagem profunda da alma"1 (SIMON, 1965, p. 202). 
Colette também atuou como jornalista e correspondente durante o período da Primeira Guerra Mundial, quando, vivendo em Veneza, na Itália, escreveu e enviou "crônicas e artigos brilhantes que chamarão a atenção de Marcel Proust"2 (LAGARDE; MICHARD, 1973, p. $523)$.

Sua obra literária, designada por Bourbonnais (1993) como sendo semi-autobiográfica, uma vez que toda obra da autora provém da união de ficção com fatos e memórias de vida, abrange títulos como Claudine à l'école (1900), Claudine s'en va (1903), La vagabonde (1910), Chéri (1920), Sido (1929) e La chatte (1933) - e rendeu a Colette notoriedade e diversos títulos, como membro da Académie Royale de Langue et de Littérature Françaises de Belgique e da Académie Goncourt. Em 1953, um ano antes de sua morte, a autora foi elevada à categoria de grand-officier da Légion d'Honneur.

O estilo da escrita de Colette, conforme Bourbonnais (1993), que também o qualifica como luxuoso, é permeado, sobretudo, pela intertextualidade e por alusões literárias, frutos de uma infância dividida entre os prazeres infantis e as horas que passava no campo ou cercada pelos livros da biblioteca de seus pais. Elementos autobiográficos combinados com o estudo dos modos e costumes sociais da época, mesclados às paisagens da Bourgogne e da Provence, às memórias de infância, tudo descrito de maneira a exprimir sensações frescas e novas; os objetos, em Colette, não são somente nomeados, mas ressuscitados (LAGARDE; MICHARD, 1973).

Para Simon (1965), Colette soube transformar o banal em matéria-prima para uma literatura franca, de um estilo "suculento e frutado", resultando em uma prosa poética fluida, originária de uma fonte inesgotável. Sua matéria-prima era tudo aquilo que era referente à sua vida:

\footnotetext{
Os contratempos da história mal a tocavam: os acontecimentos, para ela, eram a sucessão das estações, as cores dos dias, as aventuras de seus animais de estimação e de seus amigos e, certamente, seus livros, onde ela colocava, empanturrando sua frase, às vezes até o limite, de sangue e seiva, suas lembranças e suas sensações ${ }^{3}$ (SIMON, 1965, p. 28-29).
}

Bouty (1972, p. 163) faz também alusão ao mesmo fato, quando diz que "o mérito de Colette é o de pintar com ternura e poesia fatos que formam uma vida" ${ }^{4}$. E para Leguen (2007), Colette criou, mantendo uma atitude livre e libertária e com um estilo difícil de definir, uma literatura na qual constam elementos de sua experiência de vida, distanciada de qualquer escola ou corrente literária, cultivando sempre a linguagem da sensação.

Examinando a obra de Colette, e mais especificamente La maison de Claudine, que foi 
publicado pela primeira vez em 1922 - mais de 20 anos após a publicação do primeiro livro de Colette, Claudine à l'école (1900), da famosa série Claudine (BEAUMARCHAIS e COUTY, 1994) -, pode-se constatar que se trata de uma coletânea de textos que já haviam sido publicados no Le Matin, na coluna intitulada Contes des mille et un matins. Além disso, o título do livro faz referência à coleção de histórias juvenis, sendo esta a única relação existente entre as publicações da série Claudine e o livro em questão (La maison de Claudine), que não se configura como parte desse universo literário infanto-juvenil:

O título dessa coletânea de lembranças de infância, de nome Claudine, a heroína muito conhecida das primeiras obras de Colette (ver Claudine à l'école), se explica, sem dúvida, pela vontade do editor de garantir o sucesso da obra ${ }^{5}$ (BEAUMARCHAIS; COUTY, 1994, p. 1176).

O livro, como descrevem Beaumarchais e Couty (1994), é constituído por 35 contos autobiográficos, independentes entre si e organizados em ordem cronológica, que giram em torno de temáticas suscitadas por memórias como sensações, emoções e descobertas da escritora: a infância e a adolescência, sua idade adulta, a morte de seu pai e o envelhecimento de sua mãe, chegando até a infância de sua filha, o que suscita a ideia de um recomeço, símbolo para o ciclo da vida. Lembranças da relação com seus irmãos e com seus pais, com os animais domésticos, com a casa onde foi criada, caracterizam a obra com profunda nostalgia. La Maison de Claudine, assim como tantas outras obras de Colette, é um mosaico de memórias da vida da autora e o resultado da fusão entre ficção e (auto) biografia.

O mesmo acontece no conto "Ma mère et les livres", no qual se encontram lembranças de uma Colette ainda adolescente, que tinha como uma de suas principais paixões a leitura. A casa onde habitava possuía um dos melhores refúgios possíveis para essa jovem: uma biblioteca, e mesmo antes de saber ler as palavras escritas nos livros, ela já se enroscava "em bola entre dois tomos do Larousse, como um cachorro em sua casinha"6 (COLETTE, 1960, p. 32). No conto, a ávida leitora infante coloca os livros como membros importantes de sua família; por diversas vezes, as obras, que auxiliaram inclusive na educação e amadurecimento das crianças da família, deixaram de ser tratadas como meros objetos e foram personificadas, por meio da utilização de verbos e adjetivos específicos, como no trecho: "Há muito tempo eu já havia esquecido o autor de uma Enciclopédia vestida de vermelho [...]"” (COLETTE, 1960, p. 33, grifo nosso), no qual a escritora utiliza o verbo "habiller" (vestir, em francês). Em outros momentos, no entanto, os livros voltam ao seu status de objetos, porém são objetos 
dotados de uma preciosidade acalentadora, são baús que encerram tesouros e guardam segredos que intrigam até a própria Colette-personagem.

Algumas outras obras encontradas na biblioteca familiar receberam os nomes de seus próprios autores, como Voltaire, Musset, Flammarion e Zola, para designá-las. Tanto isto quanto o fato de que Colette faz referências a personagens de outras histórias, como é o caso do Gato de Botas, de Charles Perrault, refletem uma característica muito recorrente nas obras da autora: a facilidade de utilização de uma intertextualidade de qualidade fluida em seus textos, a qual pode até passar desapercebida pelos leitores menos atentos.

Já a biblioteca ganha ares de paraíso literário, sendo um dos locais mais atrativos da residência da família Colette, devido às quase infinitas possibilidades de sonhos, aventuras e sensações proporcionadas pelos livros, mas vividas naquela mesma "sala encantada":

Com sete anos, a menina já havia lido bastante, e muitos livros estavam acima de sua faixa etária: a Comédia humana, os Miseráveis, os afrescos sociais de Zola. Ela sabia, além disso, inúmeras coisas, tanto naturais quanto maravilhosas, graças a uma mãe carinhosa e bondosa que não cessava em lhe dizer: "Veja". ${ }^{8}$ (BOURIN e ROUSSELOT, 1966, p. 77)

É possível, também, notar no conto frequentes alusões às relações de seus pais e irmãos com todo aquele universo literário, além de descrições certamente fiéis à realidade, que permeia e fundamenta este conto (e tantos outros), de Colette, que cresceu cercada por livros.

\section{2. "Ma mère et les livres/ Minha mãe e os livros"}

\begin{tabular}{|c|c|}
\hline $\begin{array}{l}\text { La lampe, par l'ouverture } \\
\text { supérieure de l'abat-jour, éclairait une } \\
\text { paroi cannelée de dos de livres, reliés. Le } \\
\text { mur opposé était jaune, du jaune sale des } \\
\text { dos de livres brochés, lus, relus, } \\
\text { haillonneux. Quelques "traduits de } \\
\text { l'anglais » - un franc vingt-cinq - } \\
\text { rehaussaient de rouge le rayon du bas. } \\
\text { À mi-hauteur, Musset, Voltaire, et } \\
\text { les Quatre Évangiles brillaient sous la }\end{array}$ & $\begin{array}{l}\text { A lâmpada, pela abertura superior } \\
\text { do abajur, clareava uma parede canelada } \\
\text { de lombadas de livros, reunidos. A parede } \\
\text { oposta era amarela, do amarelo sujo das } \\
\text { lombadas de livros em brochura, lidos, } \\
\text { relidos, esfarrapados. Alguns "traduzidos } \\
\text { do inglês" - um franco e vinte e cinco - } \\
\text { realçavam em vermelho a prateleira de } \\
\text { baixo. }\end{array}$ \\
\hline
\end{tabular}


basane feuille-morte. Littré, Larousse et Becquerel bombaient des dos de tortues noires. D'Orbigny, déchiqueté par le culte irrévérencieux de quatre enfants, effeuillait ses pages blasonnées de dahlias, de perroquets, de méduses à chevelures roses et d'ornithorynques.

Camille Flammarion, bleu, étoilé d'or, contenait les planètes jaunes, les cratères froids et crayeux de la lune, Saturne qui roule, perle irisée, libre dans son anneau...

Deux solides volets couleur de glèbe reliaient Élisée Reclus. Musset, Voltaire, jaspés, Balzac noir et Shakespeare olive...

Je n'ai qu'à fermer les yeux pour revoir, après tant d'années, cette pièce maçonnée de livres. Autrefois, je les distinguais aussi dans le noir. Je ne prenais pas de lampe pour choisir l'un d'eux, le soir, il me suffisait de pianoter le long des rayons. Détruits, perdus et volés, je les dénombre encore. Presque tous m'avaient vue naître.

Il y eut un temps où, avant de savoir lire, je me logeais en boule entre deux tomes du Larousse comme un chien dans sa niche. Labiche et Daudet se sont insinués, tôt, dans mon enfance heureuse, maîtres condescendants qui jouent avec un élève familier. Mérimée vint en même os Quatro Evangelhos brilhavam sob sua capa de couro envelhecido. Littré, Larousse e Becquerel estufavam suas costas de tartarugas negras. D'Orbigny, despedaçado pelo culto irreverente de quatro crianças, desfolhava suas páginas adornadas de dálias, de papagaios, de medusas de cabeleiras rosas e de ornitorrincos.

Camille Flammarion, azul, estrelado em ouro, continha os planetas amarelos, as crateras frias e porosas da lua, Saturno que rola, pérola iridescente, livre em seu anel...

Duas sólidas abas cor de gleba ligavam o Élisée Reclus. Musset, Voltaire, jaspeados, Balzac negro e Shakespeare oliva...

Eu só tenho que fechar os olhos para rever, após tantos anos, esta peça construída com livros. Antigamente, eu também os distinguia no escuro. Eu não precisava de lâmpada para escolher algum deles, à noite, me bastava dedilhar ao longo das prateleiras. Destruídos, perdidos e roubados, eu os enumero ainda. Quase todos me viram nascer.

Houve um tempo no qual, antes de saber ler, eu me enroscava em bola entre dois tomos do Larousse como um cachorro em sua casinha. Labiche e Daudet se insinuaram, cedo, na minha 
temps, séduisant et dur, et qui éblouit parfois mes huit ans d'une lumière inintelligible. Les Misérables aussi, oui, les Misérables - malgré Gavroche ; mais je parle là d'une passion raisonneuse qui connut des froideurs et de longs détachements. Point d'amour entre Dumas et moi, sauf que le Collier de la Reine rutila, quelques nuits, dans mes songes, au col condamné de Jeanne de la Motte. Ni l'enthousiasme fraternel, ni l'étonnement désapprobateur de mes parents n'obtinrent que je prisse de l'intérêt aux Mousquetaires...

De livres enfantins, il n'en fut jamais question. Amoureuse de la Princesse en son char, rêveuse sous un si long croissant de lune, et de la Belle qui dormait au bois, entre ses pages prostrée ; éprise du Seigneur Chat botté d'entonnoirs, j'essayai de retrouver dans le texte de Perrault les noirs de velours, l'éclair d'argent, les ruines, les cavaliers, les chevaux aux petits pieds de Gustave Doré; au bout de deux pages je retournais, déçue, à Doré. Je n'ai lu l'aventure de la Biche, de la Belle, que dans les fraîches images de Walter Crane. Les gros caractères du texte couraient de l'un à l'autre tableau comme le réseau de tulle uni qui porte les médaillons espacés d'une dentelle. Pas un feliz infância, mestres condescendentes que brincam com um familiar aprendiz. Mérimée veio ao mesmo tempo, sedutor e difícil, e algumas vezes ofuscou meus oito anos com uma luz ininteligível. Os Miseráveis também, sim, os Miseráveis apesar de Gavroche; mas eu falo aqui de uma paixão racional que conheceu a frieza e as longas separações. Não havia amor entre Dumas e eu, exceto o Colar da Rainha que ardeu, algumas noites, nos meus sonhos, no pescoço condenado de Jeanne de la Motte. Nem o entusiasmo fraterno, nem o espanto desaprovador de meus pais conseguiram que eu me interessasse pelos Mosqueteiros...

Em relação aos livros infantis, nunca houve qualquer dúvida. Apaixonada pela Princesa em sua carruagem, sonhadora sob um longo crescente de lua, e pela Bela que dormia no bosque, entre suas páginas prostrada; apaixonada pelo Senhor Gato de botas de funil, eu tentava reencontrar no texto de Perrault as noites de veludo, o brilho da prata, as ruínas, os cavaleiros, os cavalos de pés pequenos de Gustave Doré; ao final de duas páginas eu retornava, desapontada, a Doré. Só li as aventuras da Cerva, da Bela, nas frescas imagens de Walter Crane. As grandes letras do texto corriam de um quadro a outro como uma 
mot n'a franchi le seuil que je lui barrais. Où s'en vont, plus tard, cette volonté énorme d'ignorer, cette force tranquille employée à bannir et à s'écarter ? ...

Des livres, des livres, des livres... Ce n'est pas que je lusse beaucoup. Je lisais et relisais les mêmes. Mais tous m'étaient nécessaires. Leur présence, leur odeur, les lettres de leurs titres et le grain de leur cuir... Les plus hermétiques ne m'étaient-ils pas les plus chers? Voilà longtemps que j'ai oublié l'auteur d'une Encyclopédie habillée de rouge, mais les références alphabétiques indiquées sur chaque tome composent indélébilement un mot magique : Aphbicécladiggalhymaroidphorebstevanz y. Que j'aimai ce Guizot, de vert et d'or paré, jamais déclos! Et ce Voyage d'Anarcharsis inviolé! Si l'Histoire du Consulat et de l'Empire échoua un jour sur les quais, je gage qu'une pancarte mentionne fièrement son "état de neuf » ...

Les dix-huit volumes de SaintSimon se relayaient au chevet de ma mère, la nuit ; elle y trouvait des plaisirs renaissants, et s'étonnait qu'à huit ans je ne les partageasse pas tous.

- Pourquoi ne lis-tu pas SaintSimon? me demandait-elle. C'est curieux de voir le temps qu'il faut à des enfants rede de tule que carrega os medalhões espaçados de uma renda. Nem uma palavra cruzou o limite que eu lhes impunha. Para onde se vão, mais tarde, esta vontade enorme de ignorar, esta força tranquila empregada para banir e para se afastar?...

Livros, livros, livros... Não que eu lesse muito. Lia e relia os mesmos. Mas todos me eram necessários. Sua presença, seu cheiro, as letras de seus títulos e a textura de seu couro... Os mais herméticos não me eram os mais caros? Há muito tempo que eu esqueci o autor de uma Enciclopédia vestida de vermelho, mas as referências alfabéticas indicadas em cada tomo compõem indelevelmente uma palavra mágica: Aphbicécladiggalhymaroidphorebstevanz y. Como amei este Guizot, em verde e ouro paramentado, nunca aberto! E esse Voyage d'Anarcharsis inviolado! Se a Histoire du Consulat et de l'Empire atracou um dia no cais, eu aposto que uma placa menciona orgulhosamente sua “condição de novo"...

Os dezoito volumes de SaintSimon se revezavam na cabeceira de minha mãe à noite; ela encontrava neles prazeres renascentes, e se surpreendia que eu, com oito anos, não os compartilhasse todos. 
pour adopter des livres intéressants !

Beaux livres que je lisais, beaux livres que je ne lisais pas, chaud revêtement des murs du logis natal, tapisserie dont mes yeux initiés flattaient la bigarrure cachée... J'y connus, bien avant l'âge de l'amour, que l'amour est compliqué et tyrannique et même encombrant, puisque ma mère lui chicanait sa place.

- C'est beaucoup d'embarras, tant d'amour, dans ces livres, disait-elle. Mon pauvre Minet-Chéri, les gens ont d'autres chats à fouetter, dans la vie. Tous ces amoureux que tu vois dans les livres, ils n'ont donc jamais ni enfants à élever, ni jardin à soigner? Minet-Chéri, je te fais juge : est-ce que vous m'avez jamais, toi et tes frères, entendue rabâcher autour de l'amour comme ces gens font dans les livres? Et pourtant je pourrais réclamer voix au chapitre, je pense; j'ai eu deux maris et quatre enfants!

Les tentants abîmes de la peur, ouverts dans maint roman, grouillaient suffisamment, si je m'y penchais, de fantômes classiquement blancs, de sorciers, d'ombres, d'animaux maléfiques, mais cet au-delà ne s'agrippait pas, pour monter jusqu'à moi, à mes tresses pendantes, contenus qu'ils étaient par quelques mots conjurateurs...
- Por que você não lê Saint-Simon? ela me perguntava. É curioso ver o tempo que leva para as crianças adotarem livros interessantes!

Belos livros que eu lia, belos livros que eu não lia, revestimento quente das paredes de minha residência natal, tapeçaria na qual meus olhos iniciados lisonjeavam os matizes escondidos... Eu conheci ali, muito antes da idade do amor, que o amor é complicado e tirânico e mesmo incômodo, já que minha mãe lhe contestava seu lugar.

- É bem embaraçoso, tanto amor, nesses livros, ela dizia. Meu pobre Gatinho-Querido, as pessoas têm outros gatos para espantar na vida. Todos esses apaixonados que você vê nesses livros nunca têm filhos para educar, nem jardim para cuidar? Gatinho-Querido, eu a faço juíza: vocês já me escutaram, você e seus irmãos, repetir sobre amor como essas pessoas fazem nos livros? E, no entanto, eu poderia reivindicar voz no capítulo, eu acho; eu tive dois maridos e quatro filhos!

Os tentadores abismos do medo, abertos em numerosos romances, fervilhavam suficientemente, se eu me inclinasse, de fantasmas classicamente brancos, de feiticeiros, de sombras, de animais maléficos, mas este além não se agarrava, para subir até mim, em minhas 


\begin{tabular}{|c|c|}
\hline $\begin{array}{l}\text { - Tu as lu cette histoire de } \\
\text { fantôme, Minet-Chéri ? Comme c'est joli, } \\
\text { n'est-ce pas? Y a-t-il quelque chose de } \\
\text { plus joli que cette page où le fantôme se } \\
\text { promène à minuit, sous la lune, dans le } \\
\text { cimetière? Quand l'auteur dit, tu sais, } \\
\text { que la lumière de la lune passait au } \\
\text { travers du fantôme et qu'il ne faisait pas } \\
\text { d'ombre sur l'herbe... Ce doit être } \\
\text { ravissant, un fantôme. Je voudrais bien } \\
\text { en voir un, je t'appellerais. } \\
\text { Malheureusement ils n'existent pas. Si je } \\
\text { pouvais me faire fantôme après ma vie, je } \\
\text { n'y manquerais pas, pour ton plaisir et } \\
\text { pour le mien. Tu as lu aussi cette stupide } \\
\text { histoire d'une morte qui se venge? Se } \\
\text { du délire romanesque, et me porta un peu } \\
\text { infaillible - à raisonner quand je n'aurais } \\
\text { venger, je vous demande un peu! Ce ne } \\
\text { encore en cela ma mère, qu'une candeur } \\
\text { serait pas la peine de mourir, si on ne } \\
\text { devenait pas plus raisonnable après } \\
\text { qu'avant. Les morts, va, c'est un bien } \\
\text { tranquille voisinage. Je n'ai pas de tracas } \\
\text { avec mes voisins vivants, je me charge de } \\
\text { n'en avoir jamais avec mes voisins } \\
\text { morts! }\end{array}$ & $\begin{array}{l}\text { tranças penduradas, contidos como } \\
\text { estavam por algumas palavras } \\
\text { conjurantes... } \\
\text { - Você leu esta história de } \\
\text { fantasma, Gatinho-Querido? Como é } \\
\text { bonita, não é mesmo? Tem alguma coisa } \\
\text { mais bonita que esta página na qual o } \\
\text { fantasma caminha à meia-noite, sob a lua, } \\
\text { no cemitério? Quando o autor diz, você } \\
\text { sabe, que a luz da lua passava através do } \\
\text { fantasma e que ele não fazia sombra sobre } \\
\text { a grama... Deve ser lindíssimo, um } \\
\text { fantasma. Gostaria muito de ver um, eu } \\
\text { chamaria você. Infelizmente eles não } \\
\text { existem. Se eu pudesse me tornar } \\
\text { fantasma depois da minha vida, não } \\
\text { perderia isso, para seu e meu prazer. Você } \\
\text { leu também esta história tola de uma } \\
\text { morta que se vinga? Se vingar, eu } \\
\text { pergunto a você! Não valeria a pena } \\
\text { morrer, se depois a gente não se tornasse } \\
\text { mais sensato que antes. Os mortos, vai, } \\
\text { são uma muito tranquila vizinhança. Eu } \\
\text { não tenho problemas com meus vizinhos } \\
\text { vivos, eu me cuido para não os ter nunca } \\
\text { com meus vizinhos mortos! } \\
\text { em tudo, resguardou-me do delírio } \\
\text { tomanesco, e me carregou um pouco mais } \\
\text { peria ter sido apenas uma vítima eu resistia a tais livros cujo }\end{array}$ \\
\hline
\end{tabular}


particulière inclinait à nier le mal, ce pendant que sa curiosité le cherchait et le contemplait, pêle-mêle avec le bien, d'un œil émerveillé ?

- Celui-ci ? Celui-ci n'est pas un mauvais livre, Minet-Chéri, me disaitelle. Oui, je sais bien, il y a cette scène, ce chapitre... Mais c'est du roman. Ils sont à court d'inventions, tu comprends, les écrivains, depuis le temps. Tu aurais pu attendre un an ou deux, avant de le lire... Que veux-tu! débrouille-toi làdedans, Minet-Chéri. Tu es assez intelligente pour garder pour toi ce que tu comprendras trop ... Et peut-être n'y at-il pas de mauvais livres...

Il y avait pourtant ceux que mon père enfermait dans son secrétaire en bois de thuya. Mais il enfermait surtout le nom de l'auteur.

- Je ne vois pas d'utilité à ce que ces enfants lisent Zola!

Zola l'ennuyait, et plutôt que d'y chercher une raison de nous le permettre ou de nous le défendre, il mettait à l'index un Zola intégral, massif, accru périodiquement d'alluvions jaunes.

- Maman, pourquoi est-ce que je ne peux pas lire Zola?

Les yeux gris, si malhabiles à mentir, me montraient leur perplexité :

- J'aime mieux, évidemment, que tu intoxicada. Será que eu imitava minha mãe nisso também, que uma candura particular levava a negar o mal, isso enquanto sua curiosidade o buscava e o contemplava, misturado com o bem, com um olhar maravilhado?

- Este aqui? Este aqui não é um livro ruim, Gatinho-Querido, ela me dizia. Sim, eu bem sei, tem esta cena, este capítulo..., mas é um romance. Eles ficam sem histórias, você compreende, os escritores, com o tempo. Você poderia esperar um ano ou dois, antes de lê-lo... O que você quer! Vire-se aí, GatinhoQuerido. Você é inteligente o suficiente para manter para si mesma aquilo que você compreende demais... E talvez não existam maus livros...

Entretanto existiam aqueles que meu pai trancava em sua escrivaninha em madeira de cedro. Mas ele trancava sobretudo o nome do autor.

- Eu não vejo utilidade em que as crianças leiam Zola!

Zola o entediava, e antes de buscar nele uma razão de nos permiti-lo ou de proibi-lo, ele colocava no index um Zola integral, massivo, acrescido periodicamente de aluviões amarelos.

- Mamãe, por que eu não posso ler Zola?

Os olhos cinzentos, tão inábeis a 
ne lises pas certains Zola...

- Alors, donne-moi ceux qui ne sont pas « certains »?

Elle me donna La Faute de l'Abbé Mouret et le Docteur Pascal, et Germinal. Mais je voulus, blessée qu'on verrouillât, en défiance de moi, un coin de cette maison où les portes battaient, où les chats entraient la nuit, où la cave et le pot à beurre se vidaient mystérieusement - je voulus les autres. Je les eus. Si elle en garde, après, de la honte, une fille de quatorze ans n'a ni peine ni mérite à tromper des parents au cœur pur. Je m'en allai au jardin, avec mon premier livre dérobé. Une assez douceâtre histoire d'hérédité l'emplissait, mon Dieu, comme plusieurs autres Zola. La cousine robuste et bonne cédait son cousin aimé à une malingre amie, et tout se fût passé comme sous Ohnet, ma foi, si la chétive épouse n'avait connu la joie de mettre un enfant au monde. Elle lui donnait le jour soudain, avec un luxe brusque et cru de détails, une minutie anatomique, une complaisance dans la couleur, l'odeur, l'attitude, le cri, où je ne reconnus rien de ma tranquille compétence de jeune fille des champs. Je me sentis crédule, effarée, menacée dans mon destin de petite femelle... Amours des bêtes paissantes, chats coiffant les mentir, me mostravam sua perplexidade:

- Eu prefiro, evidentemente, que você não leia certos Zola...

- Então, você me dá aqueles que não são os “certos"?

Ela me dava O crime do padre Mouret e o Doutor Pascal, e Germinal. Mas eu quis, magoada que os trancassem, por desconfiança de mim, um canto dessa casa onde as portas batiam, onde os gatos entravam à noite, onde a adega e o pote de manteiga se esvaziavam misteriosamente - eu quis os outros. Eu os tive. Se ela guarda disso, afinal, vergonha, uma moça de quatorze anos não tem nem pena nem mérito ao enganar pais de coração puro. Eu fui para o jardim, com meu primeiro livro roubado. Uma história sobre hereditariedade excessivamente açucarada, meu Deus, como muitos outros Zola. A prima robusta e bondosa cedia seu primo amado a uma amiga má, e tudo se passou como em Ohnet, acredite em mim, se a esposa doente não tivesse conhecido a alegria de trazer um filho ao mundo. Ela o deu à luz subitamente, com um luxo brusco e repleto de detalhes, uma minúcia anatômica, uma complacência na cor, no cheiro, na atitude, no grito, onde eu não reconheci nada da minha tranquila competência de moça do campo. Eu me senti crédula, assustada, ameaçada no meu 
chattes comme des fauves leur proie, précision paysanne, presque austère, des fermières parlant de leur taure vierge ou de leur fille en mal d'enfant, je vous appelai à mon aide. Mais j'appelai surtout la voix conjuratrice :

- Quand je t'ai mise au monde, toi la dernière, Minet-Chéri, j'ai souffert trois jours et deux nuits. Pendant que je te portais, j'étais grosse comme une tour. Trois jours, ça paraît long... Les bêtes nous font honte, à nous autres femmes qui ne savons plus enfanter joyeusement. Mais je n'ai jamais regretté ma peine : on dit que les enfants, portés comme soi si haut, et lents à descendre vers la lumière, sont toujours des enfants très chéris, parce qu'ils ont voulu se loger tout près du coeur de leur mère, et ne la quitter qu'à regret...

En vain je voulais que les doux mots de l'exorcisme, rassemblés à la hâte, chantassent à mes oreilles: un bourdonnement argentin m'assourdissait. D'autres mots, sous mes yeux, peignaient la chair écartelée, l'excrément, le sang souillé... Je réussis à lever la tête, et vis qu'un jardin bleuâtre, des murs couleur de fumée vacillaient étrangement sous un ciel devenu jaune... Le gazon me reçut, étendue et molle comme un de ces petits lièvres que les braconniers apportaient, destino de pequena fêmea... Amores de animais pastando, gatos lambendo gatas como bestas suas presas, precisão camponesa, quase austera, fazendeiras falando de sua novilha virgem ou de sua filha com angústia em conceber, eu os chamava em meu socorro. Mas eu chamava, sobretudo, a voz conjurante:

- Quando eu a coloquei no mundo, você, a última, Gatinho-Querido, eu sofri três dias e duas noites. Enquanto eu a carregava, estava grande como uma torre. Três dias, isso parece muito... Os animais nos fazem afronta, a nós outras fêmeas que não sabemos mais parir alegremente. Mas eu nunca me arrependi da minha dor: diz-se que as crianças, carregadas tão alto como você, são sempre as crianças mais queridas, porque elas queriam continuar bem perto do coração de sua mãe, e só a deixar com arrependimento...

Em vão eu queria que as doces palavras do exorcismo, recolhidas às pressas, cantassem em meus ouvidos: um zumbido prateado me ensurdecia. Outras palavras, sob meus olhos, pintavam a carne rasgada, o excremento, o sangue contaminado... Eu consegui levantar a cabeça, e vi apenas um jardim azulado, com paredes cor de fumaça que vacilavam estranhamente sob um céu que se tornou amarelo... A grama me recebeu, estendida 


\begin{tabular}{|c|c|}
\hline $\begin{array}{l}\text { frais tués, dans la cuisine. } \\
\qquad \text { Quand je repris conscience, le ciel } \\
\text { avait recouvré son azur, et je respirais, le } \\
\text { nez frotté d'eau de Cologne, aux pieds de } \\
\text { ma mère. } \\
\quad \text { - Tu vas mieux, Minet-Chéri ? } \\
\quad \text { - Oui... je ne sais pas ce que j'ai } \\
\text { eu... } \\
\qquad \text { Les yeux gris, par degrés rassurés, } \\
\text { s'attachaient aux miens. } \\
\text { - Je le sais, moi... Un bon petit } \\
\text { appliqué... } \\
\quad \text { Je restais pâle et chagrine, et ma } \\
\text { mère se trompa : } \\
\text { - Laisse donc, laisse donc... Ce n'est pas } \\
\text { si terrible, va, c'est loin d'être si terrible, } \\
\text { l'arrivée d'un enfant. Et c'est beaucoup } \\
\text { plus beau dans la réalité. La peine qu'on } \\
\text { y prend s'oublie si vite, tu verras !... La } \\
\text { preuve que toutes les femmes l'oublient, } \\
\text { est n'y a jamais que les hommes - ça le regardait, voyons, ce font des histoires... }\end{array}$ & 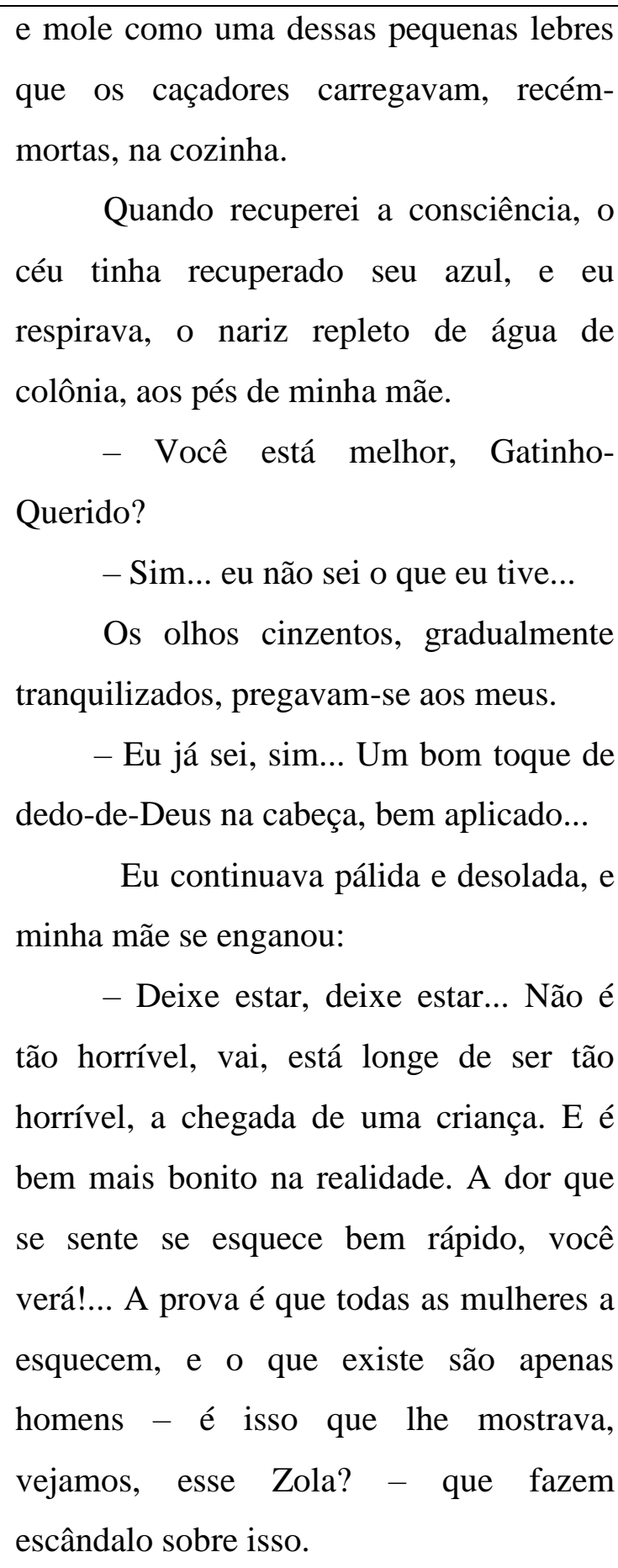 \\
\hline
\end{tabular}

\section{O úbere "Ma mère et les livres"}

Não apenas o conto "Ma mère et les livres", mas toda a obra de Colette é fonte abundante de referências literárias alinhavadas a relatos e descrições de experiências reais, sempre retomando a ideia de uma escrita livre e fértil, como os animais que figuram no conto em questão. Ao mesmo tempo, cria um estilo luxuoso, no qual cada palavra é intencional, o 
que resulta em uma “ 'glutonaria fonética', o gosto por certas palavras, por sua musicalidade, pelos estados que desperta, por seu poder evocativo e invocativo"9 (LEGUEN, 2007, p. 180). Assim, cultivando a "linguagem das sensações" (LEGUEN, 2007; MONTENOT, 2011), com as descrições de cheiros, paisagens, cores, sons e texturas, o texto de Colette beira a inocência primitiva, sobretudo em relação às "transcrições da realidade", como colocam Bourbonnais (1993) e Montenot (2011), contrapondo-se à escrita savante e complexa, repleta de artifícios e de trabalho com as palavras, reivindicando "a supremacia do verbo"10 (BOURBONNAIS, 1993, p. 98).

Dessa forma, considerando o fato de Colette priorizar essa exatidão verbal (LEGUEN, 2007), a estratégia de tradução utilizada foi estrangeirizante, com o intuito de manter o texto de chegada o mais "próximo" possível do texto de partida - mantendo a estranheza e as marcas culturais do original, afastando-se o máximo possível de uma tradução etnocêntrica, sendo o etnocêntrico definido como algo que "traz tudo à sua própria cultura, às suas normas e valores, e considera o que se encontra fora dela - o Estrangeiro - como algo negativo, ou, no máximo, bom para ser anexado, adaptado, para aumentar a riqueza desta cultura." 170 (BERMAN, 2013, p. 39). No geral, a sintaxe do texto de partida foi mantida, mesmo que, em alguns casos, isso cause um certo desconforto e estranhamento ao leitor brasileiro. Essa postura de manter as estruturas do texto fonte vai ao encontro do projeto aqui proposto, a saber: acolher o Outro, o estrangeiro. Nesse sentido, esta tradução é guiada, principalmente pela premissa, proposta por Berman (2002), de que o tradutor deve apropriar-se do contexto do qual faz parte a obra, culminando em uma tradução estrangeirizante, na qual as características da cultura de partida são mantidas na cultura de chegada, atentando ao papel do tradutor como mediador cultural.

Isso se deve, principalmente, ao fato de ter sido feita uma análise do estilo da autora e do conto em questão, antes de esse passar pelo processo tradutório. Dessa maneira, alguns traços característicos do texto puderam ser identificados com mais facilidade, tais como o uso das metáforas enumeradas no conto, visando, assim, a manter a materialidade do texto e sua tessitura - a alteração de características relativas ao ritmo, à escolha e à utilização de determinadas palavras definitivamente modificaria aquilo que foi proposto pela autora ao tecer o conto.

Durante o processo de tradução, surgiu a problemática da transposição da palavra "glèbe", utilizada pela autora para adjetivar os dois exemplares de um determinado livro, no 
trecho "Deux solides volets couleurs de glèbe reliaient Élisée Reclus". A primeira escolha para a tradução do termo "glèbe" foi "terra", resultando em "capas cor de terra". No entanto, tal decisão tornaria claro para o leitor o que não o é, necessariamente, no original - sobretudo para os leitores menos experientes. Tendo estas palavras ("glèbe" e "gleba") grafias muito semelhantes e o mesmo significado em ambas as línguas (francês e português), foi possível manter tanto a riqueza de significado e sonoridade quanto a estranheza da palavra encontrada no original. Assim, o mesmo trecho foi traduzido para "Duas sólidas capas cor de gleba ligavam o Élisée Reclus".

Em relação à tradução da palavra "Aphbicécladiggalhymaroidphorebstevanzy", criada por Colette, é importante notar que essa "nova" palavra surge da união das iniciais contidas nas lombadas alinhadas de uma enciclopédia. A expressão perderia toda a sua "mágica" se fosse transposta para uma expressão mais compreensível. Decidiu-se, então, mantê-la idêntica àquela do original, com toda sua estranheza e sonoridade.

Na questão da tradução dos títulos dos livros aos quais a autora faz alusão, como "Voyage d'Anarcharsi" e "Histoire du Consulat et de l'Empire", a primeira opção foi transpor, para o português, ambas as titulações. No entanto, não foram encontradas publicações traduzidas, no Brasil, destes livros, assim optou-se por mantê-las como no original, deixando ao leitor a decisão de buscar mais informações sobre os mesmos. O oposto ocorreu com os títulos de Alexandre Dumas "Collier de la Reine" e "Mousquetaires", que foram traduzidos para o português, uma vez que esses já são conhecidos pelo público brasileiro e já possuem traduções publicadas em português - "O Colar da Rainha" e "Os três Mosqueteiros".

Para a tradução do trecho "Les bêtes nous font honte, à nous autres femmes qui ne savons plus enfanter joyeusement", optou-se por privilegiar a escolha que a autora fez no âmbito do sentido da palavra e também da intenção de Colette de colocar as mulheres como fêmeas, fazendo referência ao fato de que os seres humanos também são animais. Assim, o texto em português resultante é: "Os animais nos fazem afronta, a nós outras fêmeas que não sabemos mais parir alegremente". No texto-fonte encontramos o termo "enfanter", que em português poderia ser colocado como "dar à luz" ou "conceber" - expressões utilizadas exclusivamente para se referir aos seres humanos. Se alguma dessas fosse utilizada, perder-seia, então, a referência intencional, criada pela autora, à vida campestre (cercada por animais e pela natureza), que pode ser percebida quando Colette coloca que os animais suportam melhor a dor do parto do que as mulheres. Neste caso, houve uma perda, tanto no sentido de riqueza 
de significado e quanto da sonoridade do verbo "enfanter", mas compensado pela permanência da alusão e do sentido proposto no conto em francês.

No caso da expressão em francês "les gens ont d'autres chats à fouetter, dans la vie", que poderia ter sido transposta para "as pessoas têm coisas mais importantes a fazer", o que traria a perda da estranheza do texto, ao substituir uma expression figée francesa por outra, brasileira, foi decidido que seria traduzida "palavra por palavra" ("as pessoas têm outros gatos para espantar na vida"). O mesmo foi proposto para o trecho "Un bon petit coup de doigt-deDieu”, no qual a expressão de Colette "doigt-de-Dieu" foi transposta para uma expressão tão simples e, de certa maneira, tão ingênua quanto a original: "dedo-de-Deus".

Finalmente, em relação à expressão "Minet-Chéri", o apelido carinhoso que, no conto, a personagem mãe da narradora utiliza para se referir à filha, é necessário salientar que, quando esta é descomposta, as palavras que a formam significam "gatinho" e "querido", respectivamente; assim, optou-se por traduzi-la para "Gatinho-Querido". A expressão foi mantida, no texto em português, no masculino, tal qual em francês, uma vez que é nítido o propósito da autora de assim o fazê-lo no conto, posto que existem, em língua francesa, tanto 172 "minette" ("gatinha") quanto "chérie" (querida). Isso se torna mais nítido no trecho "Mon pauvre Minet-Chéri", no qual a autora também utiliza o pronome possessivo masculino "mon" (“meu”), e não o feminino " $m a "$ ("minha").

Em guisa de conclusão, a estratégia de tradução estrangeirizante guiou o processo como um todo, de maneira que a tradução mantivesse, no mínimo, a mesma estranheza criada e contida no texto original - estranheza essa causada pelas escolhas de palavras, alusões, pelo ritmo imposto ao texto e pela intertextualidade e estilo livre e fluido característicos de Colette. Dessa forma, a tradução abriga o Estrangeiro, como propõe Berman (2013), inserindo o leitor em um contexto cultural diferente do seu próprio, ao mesmo tempo que o revela para esse mesmo leitor de chegada - criando uma relação na qual há uma troca cultural, e não uma apropriação, e realizando, assim, uma tradução ética e fiel à letra.

Buscou-se com essa tradução inserir o leitor em um contexto de escrita inovador desenvolvido pela autora, que assimila os eventos por ela vividos em seu texto, chegando mesmo a passar para o leitor todo o seu amor pela leitura/literatura, assim como a relevância da literatura em seu desenvolvimento e construção de sujeito. Colette, como descreveu Montenot (2011), possuía o dom e o talento de observar e, com isso, utilizando-se de metáforas precisas e evocativas, ela soube revelar a realidade através de sua arte poética e 
literária. Cada palavra, cada metáfora que ela usou para descrever essa realidade foi cuidadosamente escolhida para criar sensações também reais no leitor. A autora "era daqueles que sabem por instinto 'que entre o real e o imaginário, há sempre o lugar da palavra, a palavra magnífica e maior que o objeto'. [...] a romancista soube, pelas felicidades da escrita, assegurar a perenidade de uma língua e, além disso, de uma civilização"11 (MONTENOT, [n. p.], 2011). Seu estilo de escrita era único: possuía música, ritmo e sensualidade particulares, que encantavam os leitores, assim como a sua liberdade, presente tanto na sua vida quanto na sua arte literária (MONTENOT, 2011).

Além dessa riqueza literária, é necessário ressaltar que um dos fatores que influenciou a escolha do texto em questão foi a possibilidade de apresentar uma tradução para o português brasileiro inédita. O segundo fator que motivou essa tradução é o fato de que se trata de uma obra escrita por uma mulher. Como bem se sabe, a divulgação de diversas obras de séculos passados ainda é escassa em nosso idioma e, sendo a tradução "a forma mais reconhecível de reescritura e a potencialmente mais influente pela sua capacidade de projetar a imagem de um autor ou de uma série de obras em outra cultura para além dos limites de sua cultura de origem" (LEFEVERE, 2007, p. 24), cabe aos tradutores a tarefa de trazer à tona tais textos, reimprimindo na história da literatura as marcas de tão fascinantes escritoras, ao garantir a sobrevivência do texto literário através da tradução (LEFEVERE, 2007).

\section{REFERÊNCIAS BIBLIOGRÁFICAS}

BEAUMARCHAIS, Jean-Pierre de; COUTY, Daniel. Dictionnaire des œuvres littéraires de langue française. Paris: Bordas, 1994.

BERMAN, Antoine. A prova do estrangeiro. Tradução de Maria Emília Pereira Chanut. Bauru: São Paulo: EDUSC, 2002.

A tradução e a letra ou o albergue do longínquo. Tradução de Marie-Hélène Torres, Mauri Furlan e Andréia Guerini. Tubarão: Copiart; Florianópolis: PGET/UFSC, 2013.

BOURBONNAIS, Nicole. Colette et la liberté d'écrire - une luxueuse intertextualité. In: Études littéraires, n. 1, v. 26, p. 97-108, 1993. Disponível em: <http://id.erudit.org/iderudit/501034ar>. Acesso em: 16 mar 2016.

BOURIN, André ; ROUSSELOT, Jean. Dictionnaire de la littérature française contemporaine. Paris: Librairie Larousse, 1966.

BOUTY, Michel. Dictionnaire des œuvres et des thèmes de la littérature française. Paris: Hachette, 1972. 
COLETTE, Sidonie-Gabrielle. Ma mère et les livres. In: La maison de Claudine,

Paris: Hachette, 1960. p. 31-37.

LAGARDE, André ; MICHARD, Laurent. Collection littéraire : textes et littérature - XX siècle. Paris: Bordas, 1973.

LEFEVERE, André. Tradução, reescrita e manipulação da fama literária. Tradução de Claudia Matos Silgmann. Bauru: EDUSC, 2007.

LEGUEN, Brigitte. Colette, la escritura de los sentidos. In: Revista de Filología Románica, vol. 24, anexo V, 2007, p. 179-186. Disponível em: < http://revistas.ucm.es/index.php /RFRM/article/view/RFRM0707220179A/ 9807 >. Acesso: 16 mar 2016.

MONTENOT, Jean. Colette, écrivaine et femme libre, est morte un 3 août. In: L'Express, Paris, 3 de agosto de 2011. Culture/Livres, [n. p.]. Disponível em: < http://www.lexpress.fr/ culture/livre/colette-ecrivaine-et-femme-libre-est-morte-un-3-aout_1017292.html >. Acesso em: 1 jul. 2017.

SIMON, Pierre-Henri. Histoire de la littérature française au $X^{\mathrm{e}}$ siècle (1900-1950). Paris: Armand Colin, 1965.

RECEBIDO EM: 24 de março de 2017

ACEITO EM: 23 de agosto de 2017

PUBLICADO EM: dezembro de 2017

\footnotetext{
* Jaqueline Sinderski Bigaton. Doutoranda e Mestre (2017) em Estudos da Tradução pela Universidade Federal de Santa Catarina (UFSC). Bacharel em Letras - Língua Francesa e Literaturas (2014) pela mesma universidade. Florianópolis, Santa Catarina, Brasil.

Lattes: http://lattes.cnpq.br/2899124672170738 E-mail: jaquelinesinderski@ gmail.com

** Sheila Cristina dos Santos. Mestranda em Estudos da Tradução pela Universidade Federal de Santa Catarina (UFSC). Bacharel em Letras - Língua Francesa e Literaturas (2015) pela mesma universidade. Florianópolis, Santa Catarina, Brasil.

Lattes: http://lattes.cnpq.br/8735210240449193 E-mail: sheilasantos100@ gmail.com

1 "paysage profond de l'âme". Todas as traduções são nossas.

2 "des chroniques et des articles brillants qui retiendront l'attention de Marcel Proust".

3 "Les secousses de l'histoire la touchaient à peine : ses événements, à elle, c'étaient la succession des saisons, la couleurs des jours, les aventures de ses animaux familiers et de ses amis et, bien entendu, ses livres, où elle mettait, gorgeant sa phrase parfois jusqu'à l'excès de sang et de sève, ses souvenirs et ses sensations".

4 "le mérite de Colette est de peindre avec tendresse et poésie faits qui forment une vie".

5 "dans le titre de ce recueil de souvenirs d'enfance, du nom Claudine, l'herö̈ne bien connue des premiers ouvrages de Colette (voir Claudine à l'école), s'explique sans doute par la volonté de l'éditeur d'assurer le succès de l'ouvrage".

6 "en boule entre deux tomes du Larousse comme un chien dans sa niche".

7 "Voilà longtemps que j'ai oublié l'auteur d'une Encyclopédie habillée en rouge [...]".

8 “À sept ans, ça petit fille avait déjà beaucoup lu, et bien des livres au-dessus de son âge : la Comédie humaine, les Misérables, les fresques sociales de Zola. Elle savait, en outre, énormement de choses, à la fois naturelles et merveilleuses, grâce à une mère attentive et bonne qui ne cessait de lui dire : "Regarde »".

9 "glotonería fonética, el gusto por ciertas palabras, por su musicalidad, por los estados que despierta, por su
} 
poder evocativo e invocativo".

10 "la suprématie du verbe".

11 “était de ceux qui savent d'instinct 'qu'entre le réel et l'imaginé, il y a toujours la place du mot, le mot magnifique et plus grand que l'objet'. [...] la romancière a su, par les bonheurs d'écriture [...], assurer la pérennité d'une langue, et, au-delà, d'une civilisation". 